\title{
Resolving Conflicts Within Multicultural Teams in Industrial Enterprises
}

\author{
Veronika Videnová, Dagmar Cagáňová, Paul Woolliscroft, Jana Makraiová, Miloš Čambál \\ Slovak University of Technology in Bratislava, Trnava, Slovakia
}

\begin{abstract}
The aim of this paper is to highlight the issue of resolving conflicts within multicultural teams in industrial enterprises. The authors build upon the concept of multiculturalism which seeks for possible ways to enable different cultures to coexist and the means of communication between them. The authors base the study on the assumption that extensively developed intercultural relationships lead to mutual understanding between people and consequently to less interpersonal conflicts. In the introduction part, the authors explain the importance of increased attention and interest in the area of multiculturalism. Industrial enterprises nowadays are increasingly aware of this issue as they become more open to different cultures and they are confronted with intensive international migration and previously isolated societies become more pluralistic. As a result of these processes, individuals are more frequently in contact with members of different cultures. "Think globally, act locally" has become a slogan for our society. This way of thinking and acting was transferred to almost all areas of life (economic, political, and educational) and it is applied in the context of schools, societies, and enterprises as well. The ability to understand and accept cultural diversity is becoming essential in the ordinary working environment. It helps to create connections between emotional perception and rational acceptance. In practice, the offer of training seminars about intercultural differences is widespread. Enterprises supporting the knowledge improvement of their own employees have understood that a friendly working environment leads to increased motivation, consequently reflected in their performance. The training focused on skills development in this area can help to reduce interpersonal misunderstandings, bring new ways of conflict resolution and harmony in the workplace and thereby also increase productivity. The authors focus on the "outdoor method" as an actual phenomenon, which is used in teaching the topic of tolerance towards cultural diversity. They describe the individual stages of this method
\end{abstract}

\footnotetext{
* The paper is a part of the submitted VEGA project No. 1/0787/12, The identification of sustainable performance key parameters in industrial enterprises within multicultural environment.

Veronika Videnová, Ing., Ph.D. candidate at the Institute of Industrial Engineering, Management and Quality, Faculty of Materials Science and Technology, Slovak University of Technology in Bratislava.

Dagmar Cagáňová, M.A., Ph.D., Associate Professor, Senior Lecturer at the Institute of Industrial Engineering, Management and Quality, Faculty of Materials Science and Technology, Slovak University of Technology in Bratislava.

Paul Woolliscroft, M.Sc., Ph.D. candidate at the Institute of Industrial Engineering, Management and Quality, Faculty of Materials Science and Technology, Slovak University of Technology in Bratislava.

Jana Makraiová, Ing., Ph.D. candidate at the Institute of Industrial Engineering, Management and Quality, Faculty of Materials Science and Technology, Slovak University of Technology in Bratislava.

Miloš Čambál, M.Sc., Ph.D., Associate Professor, Director of the Institute of Industrial Engineering, Management and Quality, Faculty of Materials Science and Technology, Slovak University of Technology in Bratislava.

Correspondence concerning this article should be addressed to Veronika Videnová, Na hlinách 56, 91701 Trnava, Slovakia. E-mail: videnova.veronika@gmail.com.
} 
and introduce a modified version of Tuson's model as an effective tool for conflict resolution in the workplace. The tools introduced in this paper, place particular emphasis on actions to prevent conflicts in the workplace. This paper builds upon the theory of knowledge processing and its role as a theoretical basis for knowledge development in the area of multiculturalism. Furthermore, it teaches us to be tolerant towards others, their habits, culture, and history. "Strangers" can be a source of experience for us and they can enrich our personal lives. Discussion of the issues surrounding multiculturalism and also the identification of sustainable key performance parameters within multicultural work environments can contribute to more effective conflict resolution in the workplace and promote awareness towards the tolerant coexistence and social cohesion.

Keywords: multiculturalism, interculturality, conflict resolution, Tuson's model, outdoor method

\section{Introduction}

If we seek to understand people, we have to try to put ourselves, as far as we can, in that particular historical and cultural background. It is not easy for a person of one country to enter into the background of another country. So there is great irritation, because one fact that seems obvious to us is not immediately accepted by the other society or does not seem obvious at all. One has to recognize that countries and people differ in their approach to life and their ways of living and thinking. If we wish to convince them, we have to use their language of the mind. (Adler, 2008, p. 69)

The submitted paper discusses the current issues of multicultural/intercultural management, through the discussion of culture and its implications on management and resolve conflicts within multicultural team in industrial enterprises. The topic of interculturality has become more important and relevant than it was in the past, this is especially so since 2004 when Slovakia joined the European Union. Industrial enterprises nowadays are increasingly aware of this issue as they become more open to different cultures and they are confronted with intensive international migration and previously isolated societies become more pluralistic. As a result of these processes, individuals are more frequently in contact with members of different cultures and there is assumption that this creates a number of various conflicts. The conflicts have always been around us and always will be in our life. After all, history is amply demonstrated. The wars between states, disputes between businesses, quarrels between friends, divorce between husband and wife have been around forever and we have become accustomed to these conflicts that they look almost normal in our everyday life.

\section{Understanding of Cultural}

Culture as a concept has many definitions and there is no single agreed definition of culture. It is commonly defined as a set of habits, relationships, feelings, art and other features that characterise a society or social group. These features regulate the behaviour and communication of culture.

Kominarec and Kominarecová (2005) state that the culture is created of shared history, experiences, traditions and social customs. It is how we behave as individuals and in groups. Sometimes the culture is considered to consist only of those parts that are visible. However, they lose their meaning without knowing the other parts of culture. They are not easily accessible. Authors consider that culture consists of two equally important parts - directly visible and invisible parts. Culture can be compared to the iceberg in Figure 1. A small part of it is above the water surface, but much larger part is hidden underneath water surface. Authors claim that, it is very important to know especially this part of culture. International managers need research into culture 
because they need to be able to predict what behaviour is typical in routine situations and how members of the culture group will behave in such situations. They should know both parts of culture. Generally, it could be said, that it is recommended for managers and others people to be attentive to both parts of iceberg, as what is perceived on the surface has its roots in bottom part.

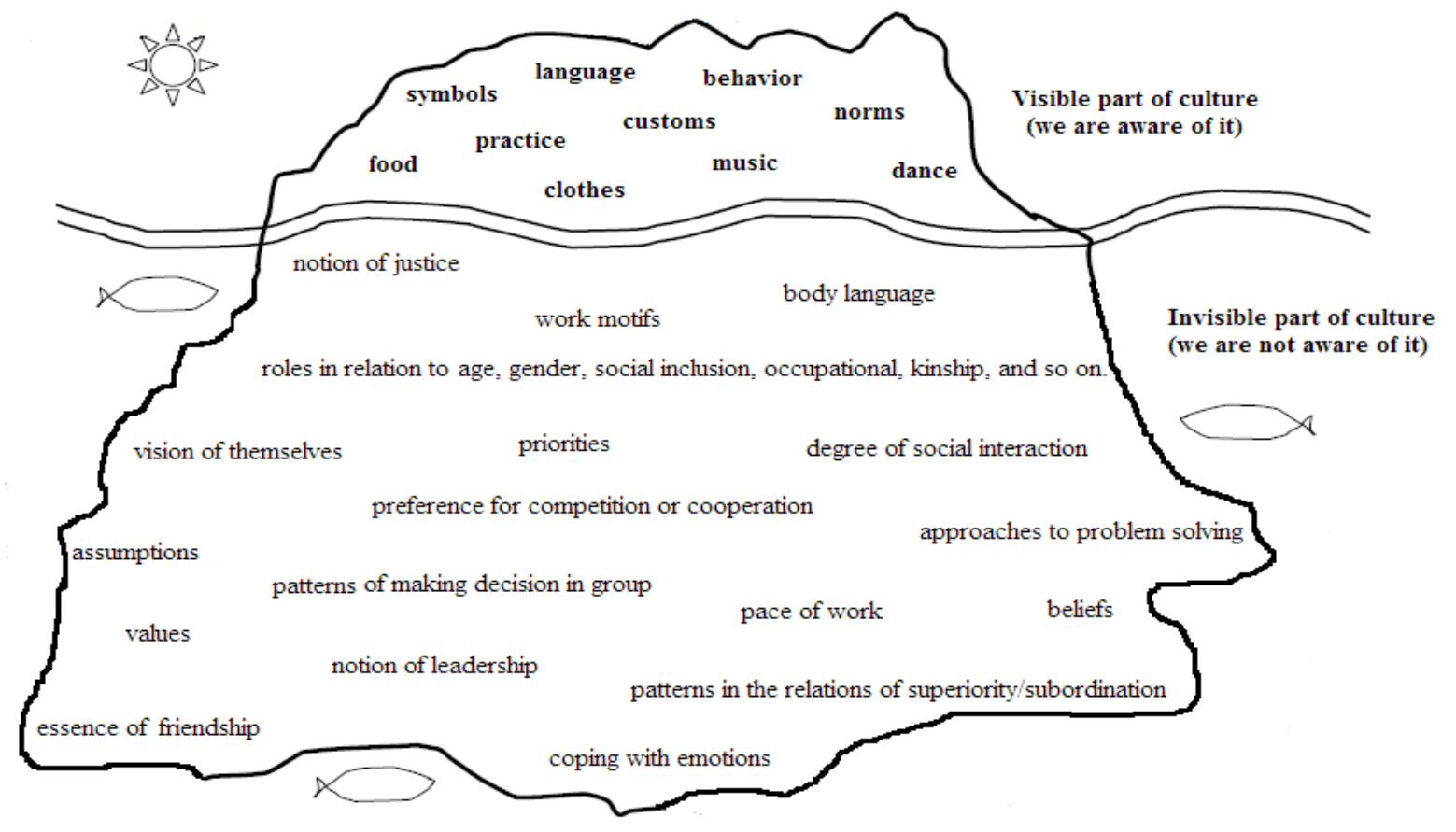

Figure 1. The cultural iceberg (Own elaboration based on Hall and Mildread, 1989).

The arrival of many foreign investors raises the important requirement - to build a corporate culture respectful of the natural Slovak working environment, but also embrace differences, brought by foreign investors. Coffield, Moseley, Hall, and Ecclestone (2008) state that corporate culture can be defined as a set of attitudes and behaviour towards its employees and stakeholders. It is mostly reflected if another competitor enters the market and in case of a merger. Mergers of companies, each coming from different cultural backgrounds can sometimes be troublesome, not only for employees, but also often with regards to the company's financial position. In this context, it is highly appropriate to apply the principles of intercultural education.

\section{Intercultural and Multicultural Management}

The globalisation of business has broadened interest in the intercultural and multicultural dimensions of management. It is necessary to understand the meaning of these terms and differences between them. Held, McGrew, Goldblatt, and Perraton (1999) state that globalisation is a process whereby worldwide interconnections in virtually every sphere of activity are growing. Some of these interconnections lead to integration/unity worldwide, others do not.

According to Landis and Wasilewska (1999), the terms cross-cultural, multicultural, and intercultural are used seemingly as having similar or at least overlapping meanings. However, these can be separated: 
- Multicultural research focuses on several (usually more than two) cultures living side by side and deals with basic psychological processes;

- Intercultural is the most dynamic term of these focusing on the interaction between cultures on an interpersonal level, for example, researching how the member of one culture is adjusting and acting in another culture.

The main difference between intercultural and multicultural management is defined below. According to authors, this paper is necessary in order to define and know this concept and differences for understanding this issue:

- Intercultural management is the most dynamic term of these focusing on the interaction between cultures on an interpersonal level, for example, researching how the member of one culture is adjusting and acting in another culture;

- Multicultural management research focuses on several (usually more than two) cultures living side by side and deals with basic psychological processes.

\section{Resolving Conflicts Within Multicultural Teams in Industrial Enterprises}

More and more often, we enter into relationships with other people from diverse culture backgrounds and environments. This can cause the emergence of various conflicts of ignorance of other people and cultures. When people think of the word "conflict", they often think of wars or violence. However, conflict exists at all levels of society in all sorts of situations. It is easy to forget that we experience conflict every day of our lives. Conflict happens when two or more people or groups have, or think they have, incompatible goals. Conflict is a fact of life. God made each of us in his own image, but he also made us unique. Therefore some of our views and opinions will differ from those of others. Conflict often occurs because of a lack of respect for one another's needs and views. However, in most cases we resolve the conflict. From a personal level to international level, good communication is usually used to overcome differences and to reach an agreement before violence breaks out. At a personal level, we often do not realise we are overcoming our differences. It is important to remember that conflict can be creative. Causes of conflict start because people do not agree about an issue. Issues of disagreement in recent large-scale conflicts include territory, language, religion, natural resources, ethnicity or race, migration, and political power. While a conflict starts because of an issue of disagreement, there are usually background influences that fuel the conflict. The most important influence is power. Others include culture, identity, and rights.

If managers want to prevent conflicts it is useful to know the concept of intercultural competence. Cagáňová, Čambál, Luptáková, and Weidlichová (2010) defined that intercultural competency is an ability to understand and interpret cultural differences, and to utilize this understanding to work effectively and successfully with members of other cultures.

\section{Resolving Conflicts at Work}

Every society, organization, group, and family creates a culture of conflict, a complex set of words, ideas, values, behaviours, attitudes, customs, and rules that powerfully influence how its members think about a respond to conflict. Cultures of conflict are shaped in and by our experiences. They set parameters for what we believe is possible when we are in conflict and define what we can reasonably expect, both of ourselves and of 
others. They shape our capacity to ask questions, alter how we see our opponents and ourselves, and tell us what is acceptable and what is not.

Every workplace and organization, school and neighborhoods, family and relationship generates spoken and unspoken rules about what we should and should not say and do when we are in conflict. Each of these entities produces a separate and distinct culture that exerts enormous pressure on us to respond to conflict in traditionally expected ways.

In conflict resolution workshops, we often ask, "What is one word or phrase that expresses what you do or feel when you are in conflict?" People's initial responses often include words like anger, frustration, silence, shame, fear, stress, avoidance, and repression, nearly all of which are negative. Authors then ask whether there are any positive outcomes from conflict, and people call out words like change, intimacy, learning, growth, opportunity, communication, resolution, forgiveness, listening, trust, and completion. The positive words represent what we all want, what is possible, and what is at stake in our conflicts, while the negative words represent how we feel, what we are doing to each other, and how we are trying to get it. But if you try to use negative means to achieve positive ends, you will quickly discover that it is nearly impossible to "get there from here" that anger does not translate into trust, any more than shame builds self-confidence. Try this yourself. Consider a recent conflict or miscommunication you experienced. List the first words that come to mind regarding your opponent, both negative and positive, without censoring yourself, and see what feelings and ideas emerge from your subconscious. Then ask yourself what led you to use the negative words, how you might implement the positive ones, and how it might be possible to resolve your conflicts by turning the negatives into positives. For example, if you feel frightened by your opponent, consider what it might take to overcome your fear, talk calmly about the problem, and let it go.

According to Wiley (2005), you may find that the positive words reflect a deeper understanding and that working through your conflict could dramatically improve your relationships and communications, while the negative ones reflect a profound frustration at your inability to do so. Yet the negative words are likely to keep you locked in conflict and stuck in cycles of distrust, while the positive ones, to become real, require you to get to the bottom of the reasons why you came up with the negative words in the first place and to honestly and empathetically participate in dialogue with your opponent. Doing so automatically starts to transform the negative words in positive ones at their source inside you. Usually often hear managers argue that conflict resolution and effective communication take too much of their time or that it costs too much to conduct a retreat at which employees work on improving their communication skills and resolving their disputes. But consider how much time and money this organization wasted by not addressing its unresolved conflicts and how little time it took to set things right. Authors rarely calculate the emotional and financial costs of living with conflict and do not consider the time it takes to not communicate effectively or not resolve our conflicts. Authors rarely include in bottom-line calculations the time people spend getting upset or sick over unresolved conflicts, the time dissipated in gossiping or talking to others about them, and the time wasted by not focusing on work. Authors do not weigh in the balance the loss of morale, motivation, customer satisfaction, and future business that result from employee unhappiness or the amount of damage inflicted on work relationships by conflicts between friends, colleagues, and co-workers. 


\section{Outdoor Methods and Tuson's Model as Effective Tools for Conflict Resolution in the Workplace}

There are a lot of possibilities about how we can resolve conflicts, but the best way is to prevent conflicts before they happen. The training focused on skills development in this area can help to reduce interpersonal misunderstandings, bring new ways of conflict resolution and harmony in the workplace and thereby also increase productivity. The authors focus on the "outdoor method" as an actual phenomenon, which is used in teaching the topic of tolerance towards cultural diversity. They describe the individual stages of this method and introduce a modified version of Tuson's model as an effective tool for conflict resolution in the workplace. The tools introduced in this paper, place particular emphasis on actions to prevent conflicts in the workplace.

The ability to understand and accept the cultural differences is increasingly important in common working environment. It helps to create the interconnection between how the differences are emotionally perceived and how they are rationally processed. In practice, within the training market, there are many seminars and courses offered in the field of multiculturalism and businesses that decided to invest in raising awareness of their employees through various learning programs have understood the importance of creating friendly working conditions within multicultural teams that consequently leads to motivation and performance increase.

The training aimed to develop intercultural tolerance skills can reduce interpersonal misunderstandings, as well as bring new ways of conflict resolutions on the workplace.

\section{Outdoor Methods}

Working life, very similar to a personal life, has its brighter and darker sides. After a certain time the working team can just like a couple slip easily into the stereotype and routine, or the exhaustion of unsolved conflicts and persistent problems can occur. Whereas the couple found themselves in this situation is advised to go for a holiday for few days or temporarily separate to find how to cope, the employers can offer their employees outdoor training, thus actively relax with plenty of activities and games, which can moreover initiate positive desired changes in an organization.

Outdoor methods are recently the most used among training methods with focus on gaining intercultural knowledge. Through creating the trustful atmosphere at outdoor activities, the working team starts to open towards the needs of all individuals who are then able and willing to point out the conflict reasons and they are ready to try to find the best ways out. The outdoor training programs are based on a theory of "experimental learning" or so called "adventure learning", which means acquisition of knowledge through you own practical experience. The firsthand experience is the best remembered one and better used in everyday life. Therefore the courses participants must face various tasks full of challenge and need for decision making, where original and unconventional solutions are mostly valued. Special case studies and physical activities are taken as model situations in this kind of learning.

Essential features of outdoor training are:

- Dynamic training programs based on first-hand experience;

- Model situations and real situations solving;

- Active participating within small groups;

- Inspirational natural surroundings. 
Outdoor training in most cases represents a combination of physical activities and learning seminars held indoors. A team learning where on one side stands a group of lecturers and on the other side group of participants is the most often used and team cooperation leads to better results, compared with individual training. This kind of training enables to include such procedures that would be difficult to apply into a common learning.

Advantages (strengths) of outdoor programs:

- The creative approaches are developed to eliminate automated activities and routine;

- Developing of fulfilled relationships rather than just formal structures;

- Active behaviour rather than passive soaking of information;

- Thanks to physical activities, the participants discover the joyfulness of physical exercising and maintaining the good physical well-being. They include the analysis and feedback.

\section{Tuson's Model}

In practice it is often seen managers or supervisors trying to manage the team of people within the international company with the evident punctuality typical for Germans, but from the perspective of Slovak employees they are very restrictive, leaving no space for flexibility and spontaneity. In the same moment we can mention emotionality and expressiveness of Italians, modesty of Britons, or Japanese esteem and shyness. Intercultural education is focused particularly on understanding and accepting of the principles of other people's acting. Every action promotes reaction and different reactions than expected can after some time reflect in uncertainty or reducing of reassurance. Resolving conflict often depends on the skill of a leader. The Tuson's model gives low priority to efficiency (doing things right) but high priority to effectiveness (doing the right things).

The authors of this paper characterize Tuson's model according to three zones in Figure 2.

"Comfort zone"-it is the zone in which an individual feels safe, and is familiar with the environment, people and the ways of working. But it is also an environment where he does not learn anything new, since he acts based on his previous experience and knowledge and primarily he does not feel the need to change anything.

"Learning zone" - or so called "stretch zone"-is represented by the space where an individual hits his current limits of abilities and skills and finds out they can be developed beyond those borders. In most cases the impulse for changing the way of acting or stepping out from worn out track comes from internal or external environment.

"Panic zone"- usually means crossing the current limits of an individual and from the perspective of gaining knowledge and skills there is no way further, because of the risk of regression, resulting from bad experience and fear.

When conducting intercultural trainings we try to get the participants from the "comfort zone" to the "learning zone" precisely by involving them into aforementioned outdoor activities. Firstly they might feel uncertain about it, like being in the unknown environment. However with gradual learning and acquiring both theoretical and practical knowledge and skills, their "comfort zone" expands.

From the intercultural perspective the "comfort zone" represents you own culture, whereas the "learning 
zone" is represented by the space for interaction with other cultures and finally the "panic zone" is a source of misunderstandings and social conflicts. The aim of outdoor learning is to simulate specific situations that can help to extend the "comfort zone" range by being active in their "learning zone". It helps to understand and respect differences, raise the motivation to cooperate and act adequately to the situation.

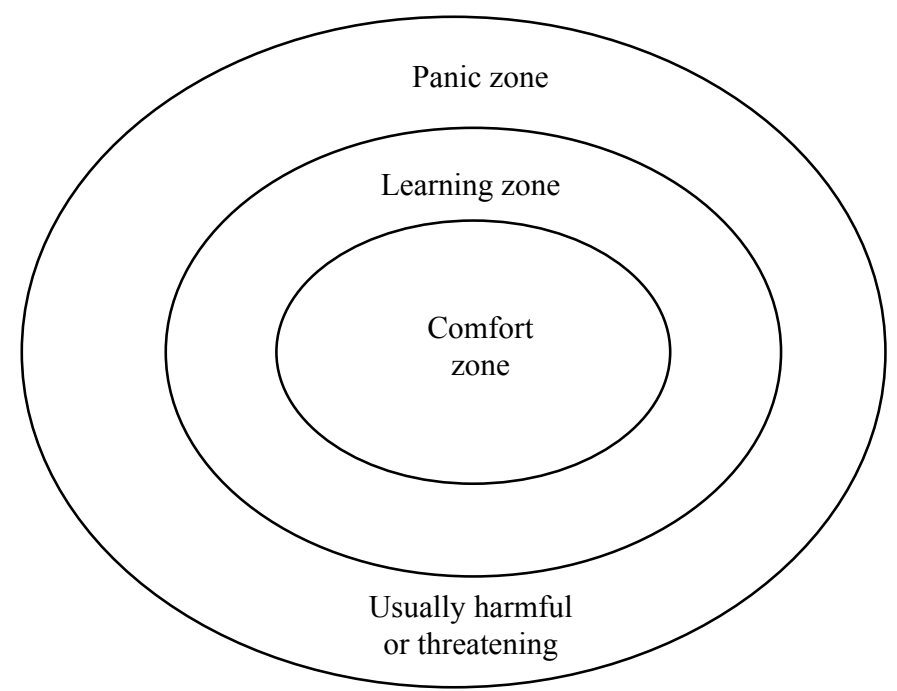

Figure 2. Tuson's model (Own elaboration based on Balogová, 2005).

\section{“KEMSAC” Strategy—Strategy of Multicultural Education}

According to Kominarec and Kominarecová (2005), KEMSAC Strategy model was originally developed in educational practice. The letters in the word KEMSAC stand for the whole processes, which are the part of this model and they will be explained below. KEMSAC model can be stated as an important tool for multicultural education as well. This way of educational orientation could offer preconditions for personal development within multicultural teams, whose individual members are able to take responsibility for their behaviors and actions, they respect each other, can contribute to smooth communication and coexistence on local as well as global level.

"K" for Knowing - the aim is to learn how to process information, develop and manage thinking, resolve conflicts using algorithms and heuristics and finally how to explore. These mentioned abilities are essential for coexistence in multicultural society.

"E" for Emotion - represented in methods for emotionality development, which are aimed to learn how to acquire a self-positive attitude, feel positive about other people, work and world. In brief, it could be conclude this is nothing more that emotional intelligence development.

"M" for Motivation - the theory tells us about ways how to motivate employees, maintain their interest in the topics, particularly the issue of multiculturalism, which supports learning from each other, mutual communication, understanding and creative problem solving. Experiential learning provides the learners personal motivation, and if we use the relational frameworks and appropriate motivators (Kolb's cycle of learning, Gardner's theory of multiple intelligence types, etc.), we can achieve high motivation in individuals which will consequently result in their success, personal development, interests and needs increase and finally problem solving competency. 
"S" for Socialization - the aim of the socialization is individual's inclusion into society by the socialization process in which the individual get familiar with the socially accepted values and dispose of undesirable (unfavorable) attitudes instead. Compared to this, when taking a new job or upon transferring to another job position, each employee has to undergo an adaptation process, which based upon active social learning and results in working, social and corporate culture adaptability. The adaptation process uses methods of which develop skills and abilities to communicate effectively, cooperate with others, help each other, but also find their own way to the satisfaction based on good relationships on all levels (intrapersonal, interpersonal, multicultural, etc.)

"A" for Autoregulation - means self-control, which represents pointing of internal energy the right way in order to master emotions, wishes and achieve personal goals. In other words, it can be said it is pointing of energy towards to the values like tolerance, respect, helpfulness, and endurance. Value education uses methods that are based on self-reflection and self-evaluation and they help to recognize personal goals, sense of being, ideas of personal fulfillment, and within the multicultural education equip team members with tools to observe the attitudes and values expressions of people from different cultures.

"C" for Creativity - means discovering new unusual ways of coexistence of cultural different people and also solving problems related to diversity in general. Methods of enhancing creativity in multicultural education are aimed at revealing ways to improve our world.

\section{Kolb’s Learning Cycle}

According to Coffield et al. (2008), learning is the process whereby knowledge is created through the transformation of experience. Kolb proposes that experiential learning has six main characteristics.

Authors of this paper identify and share Kolb's opinion that learning is the process whereby knowledge is created through the transformation of experiences. They propose to apply six main characteristics of experiential learning to use on the multicultural education and for understanding what is multicultural education.

Authors define this characteristic of multicultural learning:

- Multicultural learning is best conceived as a continuous process grounded in experience, not in terms of outcomes;

- Multicultural learning requires the resolution of conflicts between various cultures;

- Multicultural learning is a holistic process of adaptation to the world and involves transactions between the person, group, team, and the environment;

- Multicultural learning is the process of creating knowledge that is the result of the transaction between culture one country and culture of other country.

Kolb (2010) state that Kolb's learning theory sets out four distinct learning styles, which are based on a four-stage learning cycle. In this respect, Kolb's model differs from others since it offers both a way to understand individual learning styles, and also an explanation of a cycle of experiential learning that applies to all learners. "Experiential" means relating to or resulting from experience while "experimental" means relating to or based on experiment. Kolb uses the term "experiential" as his theory is based more on reflection of experiences. While others use "experimental" when referencing experimental-inquiry a technique that requires learners to test hypothesis (experiment) about content knowledge. Kolb theorized that the four combinations of 
perceiving and processing determine one of four learning styles of how people prefer to learn. Kolb believes that learning styles are not fixed personality traits, but relatively stable patterns of behavior that is based on their background and experiences. Thus, they can be thought of more as learning preferences, rather than styles.

According to authors, it is necessary to explain the importance of increased attention and interest in the area of multicultural learning. The Kolb's theory of understanding we can also apply and use for multicultural learning. It is source learning of development people which work together in workplace and they are from diverse cultures. In team, where various people work together and they have diverse culture, habits, knowledge, etc. all members are supposed to take care of each other and get to know each other. All mentioned attributes are helpful in building of stable and effective multicultural teams. Finally, it helps to increase motivation to work, productivity on workplace and performance of employees. Steps of multicultural learning process are shown in Figure 3. This figure provides a learning cycle that involves four processes that must be present for learning to occur. Depending upon the situation or environment, the learners may enter the learning cycle at any point and will best learn the new task if they practice all four modes.

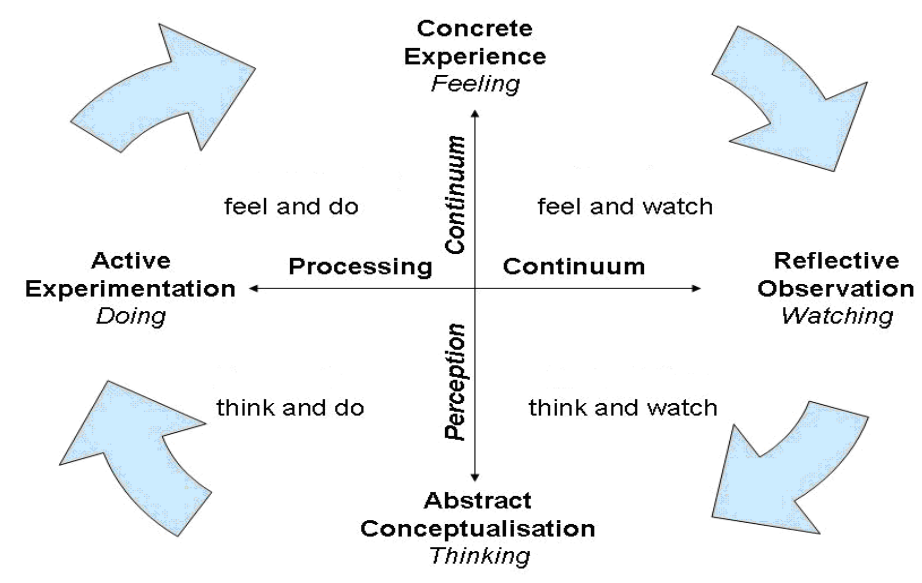

Figure 3. Kolb's learning styles (Kolb, 2010).

Steps in the learning process according to Kolb (2010):

- Concrete experience (feeling): Learning from specific experiences and relating to people. Sensitive to other's feelings;

- Reflective observation (watching): Observing before making a judgment by viewing the environment from different perspectives. Looks for the meaning of things;

- Abstract conceptualization (thinking): Logical analysis of ideas and acting on intellectual understanding of a situation;

- Active experimentation (doing): Ability to get things done by influencing people and events through action. Includes risk-taking.

Authors of this paper state some examples.

Learning to coach:

- Concrete experience-Having a coach guide you in coaching someone else;

- Active experimentation-Using your people skills with what you have learned to achieve your own coaching style; 
- Reflective observation-Observing how other people coach;

- Abstract conceptualization - Reading articles to find out the pros and cons of different methods. Learning algebra:

- Abstract conceptualization-Listening to explanations on what it is;

- Concrete experience - Going step-by-step through an equation;

- Active experimentation-Practicing;

- Reflective observation-Recording your thoughts about algebraic equations in a learning log.

\section{Conclusions}

As the whole world becomes connected and globalized, we can see the interactions of different cultures in every part of our lives, not only in professionally, but in personal relationships as well. People have various backgrounds represented in their cultural identity, they have different expectations, ways of thinking and acting, which sometimes can lead to misunderstandings and conflicts, therefore it is of great importance to place an emphasis on understanding and accepting those coming from other cultures. This is the main reasons why is necessary to know and apply multicultural education in industrial enterprises. This paper built upon the theory of knowledge processing and its role as a theoretical basis for knowledge development in the area of multicultural education. The authors explained the importance of increased attention and interest in the area of multicultural education. In the paper, the authors described the strategy of "KEMSAC" and Kolbe cycle. Kolbe cycle usually focuses on multicultural education in schools. The authors suggested this cycle to be applied for multicultural teams in industrial enterprises. Furthermore, it teaches us to be tolerant towards others, their habits, culture and history. "Strangers" can be a source of experience for us and they can enrich our personal lives.

This research in the area of multiculturalism, multicultural education and improve the performance of multicultural teams will be continue, because the authors of the article carry out the research in this area during the doctoral study.

\section{References}

Adler, N. J. (2008). International dimensions of oganizational behavior (2nd ed.). Boston, M.A.: PWS-KENT Publishing Company.

Balogová, B. (2005). Interkulturálne tréningy navodzujú atmosféru dôvery. Retrieved from http://podnikanie.etrend.sk/podnikanie-riadenie/interkulturalne-treningy-navodzuju-atmosferu-dovery.html

Cagáňová, D., Čambál, M., Luptáková, W. S., \& Weidlichová, L. (2010). Intercultural management-Trend of contemporary globalized world, 21st EAEEIE. Electronics and Electrical Engineering, 6(102), 51-54.

Coffield, F., Moseley, D., Hall, E., \& Ecclestone, K. (2008). Learning styles and pedagogy in post-16 learning: A systematic and critical review. Retrieved January 15, 2008, from http://www.lsda.org.uk/files/PDF/1543.pdf

Held, D., McGrew, A., Goldblatt, D., \& Perraton, J. (1999). Global transformation. Stanford, C.A.: Stanford University Press.

Hall, E. T., \& Mildread, R. H. (1989). Understanding cultural differences: Germans, French, and Americans. Yarmouth, Maine: Intercultural Press.

Kolb, D. (2010). Experiential learning: Experience as the source of learning and development. Englewood Cliffs, New Jersey: Prentice Hall.

Kominarec, I., \& Kominarecová, E. (2005). Multikulturalita a edukácia. Prešovská univerzita v Prešove, Fakulta humanitných a prírodných vied.

Landis, D., \& Wasilewska, J. H. (1999). Reflections on 22 years of the international. Journal of Intercultural Relations, 23(4), 535-574.

Wiley, J. (2005). Resolving conflicts at work: Eight strategies for everyone on the job. San Francisco, C.A.: Jossey-Bass. 